\title{
The pre-tracking effects of parental background
}

Citation for published version (APA):

Korthals, R. A. (2015). The pre-tracking effects of parental background. Maastricht University, Graduate School of Business and Economics. GSBE Research Memoranda No. 010 https://doi.org/10.26481/umagsb.2015010

Document status and date:

Published: 01/01/2015

DOI:

10.26481/umagsb.2015010

Document Version:

Publisher's PDF, also known as Version of record

\section{Please check the document version of this publication:}

- A submitted manuscript is the version of the article upon submission and before peer-review. There can be important differences between the submitted version and the official published version of record.

People interested in the research are advised to contact the author for the final version of the publication, or visit the DOI to the publisher's website.

- The final author version and the galley proof are versions of the publication after peer review.

- The final published version features the final layout of the paper including the volume, issue and page numbers.

Link to publication

\footnotetext{
General rights rights.

- You may freely distribute the URL identifying the publication in the public portal. please follow below link for the End User Agreement:

www.umlib.nl/taverne-license

Take down policy

If you believe that this document breaches copyright please contact us at:

repository@maastrichtuniversity.nl

providing details and we will investigate your claim.
}

Copyright and moral rights for the publications made accessible in the public portal are retained by the authors and/or other copyright owners and it is a condition of accessing publications that users recognise and abide by the legal requirements associated with these

- Users may download and print one copy of any publication from the public portal for the purpose of private study or research.

- You may not further distribute the material or use it for any profit-making activity or commercial gain

If the publication is distributed under the terms of Article $25 \mathrm{fa}$ of the Dutch Copyright Act, indicated by the "Taverne" license above, 


\section{Maastricht University}

Roxanne Korthals

The Pre-Tracking Effects of

Parental Background

RM/15/010

\section{GSBE}

Maastricht University School of Business and Economics

Graduate School of Business and Economics

P.O Box 616

NL- 6200 MD Maastricht

The Netherlands 


\title{
The Pre-Tracking Effects of Parental Background ${ }^{1}$ Roxanne Korthals
}

\begin{abstract}
Tracking students in secondary school could increase the effect of parental background $(\mathrm{PB})$ on student performance, especially if parents can influence the track choice. This influence can be either direct or indirect, and either purposefully or not. Little is known about these indirect effects of PB that could arise before tracking has taken place. In the Netherlands the track placement decision of individual students is made by secondary schools that base their decision on two performance signals that they receive from the elementary school of applying students: an elementary school exit test score and an elementary school teacher track recommendation. Using longitudinal data from the Netherlands, I find that high PB parents are able to increase their child's teacher recommendation (purposefully or not): The odds of having the highest track recommendation as compared to the other recommendations, for students whose parents have a tertiary education degree are between 1.6 and 3.6 times greater than for students whose parents only have a primary education degree. For the math exit test score I find no effect, while for reading an effect is found but not robust.
\end{abstract}

Keywords: economics of education, tracking, parental background, inequality

JEL codes: I20, I21, I24

\section{Introduction}

To go to the high track in secondary school is often perceived as something positive for all students: The status of the track is higher, teachers and the curriculum in the high track are better, there are more post-secondary schooling options after successful completion of the high track, and later outcomes (educational attainment, wages, unemployment chances) might also be positively influenced by attendance of the high track. It is therefore no surprise that most parents want their child to attend the high track. In the Netherlands the track placement decision of individual students is made by the secondary school based on two performance measures: an elementary school exit test score and an elementary school teacher track recommendation. Parents therefore have no formal route to influence the track decision.

\footnotetext{
${ }^{1}$ I would like to thank Nicolás Salamanaca, Trudie Schils, Louise Elffers, the participants of the Economics of Education group, and the $\mathrm{PhD}$ seminar group in Maastricht University for valuable comments.
} 
However, parents will still have an influence on track placement either direct or indirect, and either purposefully or not. Parents that want to exert influence on the track decision might search for new areas in which they can exert influence when they do not have direct influence. When a high elementary school exit test score gives students access to the high track, parents will exert effort to ensure a good test score for their children, either by studying with their child for the test or by providing financial means to help the child study. And when the recommendation of the elementary school teacher is important, parents might try to persuade the teacher to give the highest recommendation.

When all parents care equally about the track placement of their child and have the same amount of influence, no effect of this parental involvement can be found. However, it is likely that specific groups of parents, especially higher educated parents, have a better understanding of the importance of the elementary school exit test and the teacher recommendation and might thus exert more effort, and they might also be better able to exert influence on the track decision. It might also be that specific parents have a greater influence than others because their characteristics (unconsciously) influence teachers who provide different recommendation for students with the same performance. Whether there is a differential effect on the two track determinants due to parental education is the empirical question this paper answers. ${ }^{2}$

The aim of this paper is to examine whether a parental background (PB) effect exists on the factors that determine track placement, the two track determinants, above and beyond a PB effect on ability in general. A PB effect on ability is a common result, but whether at the moment of track placement an additional parental effect exists above this general effect has so far not been investigated. I make use of data from elementary school students in the Netherlands from before tracking has taken place. The Netherlands has a strict formal tracking regime in which students are tracked when they enter secondary school at the age of 12 (grade 7). The receiving secondary schools decide on the track placement of students and they base their decision on an elementary school exit test and the track recommendation of the elementary school teacher, which elementary schools are required to deliver them by law

\footnotetext{
${ }^{2}$ What the exact drivers are of this effect are not examined here but could range from studying together with the child, to paying for tutoring, to making sure the child goes to bed early on the nights before the test. All of these channels are most probably more affordable and require less effort for higher educated parents than for lower educated parents.
} 
(Kingdom of the Netherlands, 1981). ${ }^{3}$ Since schools are free to accept students based on their own criteria relating to the two track determinants, parents have no formal route to decide on the track choice of their child. In practice, parents can help their child study for the elementary school exit test, exert pressure on the elementary school teacher to change the track recommendation, and due to free school choice, they can try to find a school which will accept their child to the desired track.

To be able to disentangle the general PB effect on ability and the PB effect on the track determinants, I control for previous test scores which are assumed to capture the general PB effect. Since these previous tests might measure ability with error, an instrumental variable approach is used to limit the amount of measurement error in these previous tests. I then look at whether there is an additional relation between PB and the elementary school exit test and between PB and the elementary school teacher recommendation besides the common relation of PB and ability. I find that an additional PB effect does exist: For instance, the odds for students whose parents have a tertiary education degree to get the highest teacher recommendation are between 1.6 and 3.6 times greater than for students whose parents only have a primary education degree. For the reading exit test score, high PB parents are able to increase their child's reading elementary school exit test score with one sixth of a standard deviation, but this effect is less robust. I find no effect on the math exit test score. To my knowledge this is the first paper that explicitly looks at the additional PB effects that might arise in a tracked education system before the track decision has taken place.

$\mathrm{PB}$, as proxied by parental education, parental income or parental employment status, and its effect on student performance is a widely studied phenomenon. The early contributions on this field are from Girard and Bastide (1963) and Boudon (1974), sociologists who distinguished between primary and secondary PB effects. ${ }^{4,5}$ This paper uses the term general $P B$ effect for what is in the sociological literature called the primary PB effect, and additional $P B$ effect for the secondary PB effect on track placement. Primary PB effects are the direct

\footnotetext{
${ }^{3}$ In the academic year 2014/2015 the use of the elementary school exit test in deciding the track choice is severely limited by the government and secondary schools are only allowed to use the elementary school teacher track recommendation in their track placement decision.

${ }_{5}^{4}$ Jackson (2013b) provides an overview of the primary and secondary PB effects.

${ }^{5}$ Recently Esser (2014) introduced the term tertiary PB effects for the differential effect that PB has on outsiders which influence the transition of the child. For instance, teachers might give higher track recommendations to children of high $\mathrm{PB}$ given their performance than to lower PB children. Teachers might give a high PB child the benefit of the doubt since the teacher thinks that (s)he will be better supported by her/his parents or unconsciously have different expectations on the children's ability (e.g. Lavy and Sand, 2015, Barg, 2013, Jussim and Harber, 2005).
} 
effects of PB on ability or performance due to nature and nurture. Some of the mechanisms are that children from higher PB parents receive better nutrition and health care allowing them to reach their potential, these children are also read to more often which stimulates their language use and they receive a set of norms and values needed for successful educational careers. Secondary PB effects are the indirect effects of PB on performance based on different choices at important transition points. That these PB effects are not purely based on nature is shown by Black et al. (2005) who use exogenous changes in parental education and show that the education of the mother has a positive effect on the child's educational attainment. By controlling for the general PB effect (i.e. primary PB effect) with an early test score, this paper only look at the additional PB effect (i.e. secondary effect) on the two track determinants.

Tracking has often been found to increase the effect of PB on student performance (Ammermueller, 2005; Schuetz et al., 2008). ${ }^{6}$ Part of this increase in the effect of PB could be explained by a PB effect on the tracking decision. For a number of countries, studies show this positive effect of PB on track choice (See Tieben et al. (2009) for the Netherlands, Dustmann (2004) and Schneider and Schneider and Tieben (2011) for Germany, Sullivan et al. (2011) for United Kingdom, Ichou and Vallet (2011) for France, Horn (2013) for Hungary, and Panichella and Triventi (2014) for Italy). Korthals (2012) shows in a crosscountry comparison that when principals always consider prior performance in accepting the student to the school in countries that track, the effect of PB on performance is lower. The author argues that tracking is good for equal opportunities if track placement is done based on prior performance, since this lowers the influence parents have on their child's educational path. Dollman (2011) shows that the influence of PB on the track choice is indeed reduced when mandatory teacher recommendations play a role in track placement decisions. The effect of PB on the transition into a tracked system also runs through other mechanisms, for instance through the risk attitudes of the parents (Woelfel and Heineck, 2012) or on kindergarten attendance (Landvoigt et al., 2007).

Since a direct influence of parents on the track choice is very limited in the Netherlands, parents are left with using indirect influence. One way of indirect influence parents have is to help prepare their child for the elementary school exit test. Since the exit test score is one of

\footnotetext{
${ }^{6}$ However some studies find different results. Walldinger (2006) finds no effect of early tracking on the effect of PB once the PB effect in elementary school is taken into account. And also Brunello and Checchi (2007) do not find evidence for a reinforcing effect of tracking and they find tracking may even lower the effect of PB on performance after secondary school.
} 
two signals that secondary school use to base the track decision on, a higher elementary school exit test score will increase the chances of going to the higher track. To increase the test score of their child, parents can help their child study, pay for private tutoring and use other ways to help them perform better at the test. Another way to influence the track decision is to influence the elementary school teacher recommendation by convincing the teacher that a higher track choice is more suited for the child. When both these strategies did not lead to high enough signals for the secondary school to accept the child to the higher track, parents can try to convince the secondary school otherwise. Barg (2013) shows that when parents in France object to the upper secondary track recommendation of their child given by the teacher the school staff often reconsiders.

The structure of this paper is as follows. First, I present some information on the Dutch education system. Then I elaborate on the data and the methodology. Subsequently, in Sections 4 and 5, the results are presented. Finally, I conclude.

\section{The Dutch education system}

The Dutch secondary education system is a highly differentiated system with early selection into tracks at age 12 with four main tracks available to students. Figure 1 shows the complete education system of the Netherlands. The move of students into the tracked system coincides with the transition from elementary to secondary school which is at age 12 . The four tracks are practical education (PO), pre-vocational track (VMBO), and two general tracks: the track which directly leads to university of applied sciences (pre-college track, HAVO) and the track that directs leads to university (pre-university track, VWO). ${ }^{7}$ The pre-vocational track is further sub divided into 4 tracks VMBO b, VMBO $\mathrm{k}, \mathrm{VMBO} g, \mathrm{VMBO} \mathrm{t}$. VMBO b is the most practical track, while VMBO k, VMBO g, VMBO t have an increasing theoretical focus. When students first enter secondary school it is possible to enter "bridge classes" in which students from (most often) two adjoining tracks are grouped together, for instance HAVO-VWO classes or VMBO t-HAVO classes. Table 1 shows the distribution of students across track in all grades and it shows that in the seventh grade (first grade in secondary school) 80 percent of students are in such a bridge class, but most bridge classes only exist for one or two years. In grade 9 only 2 percent is still in a bridge class as can be seen in Table

\footnotetext{
${ }^{7}$ In VWO a further sib division exists for athenaeum and gymnasium. Both sub divisions offer the same type of education except that at a gymnasium school students learn Greek and/or Latin.
} 
1. Table 1 also shows that most students are in VMBO, HAVO and VWO. The practical education (PO) track contains less than 1 percent of students across all grades.

\section{Figure 1: The Dutch education system}

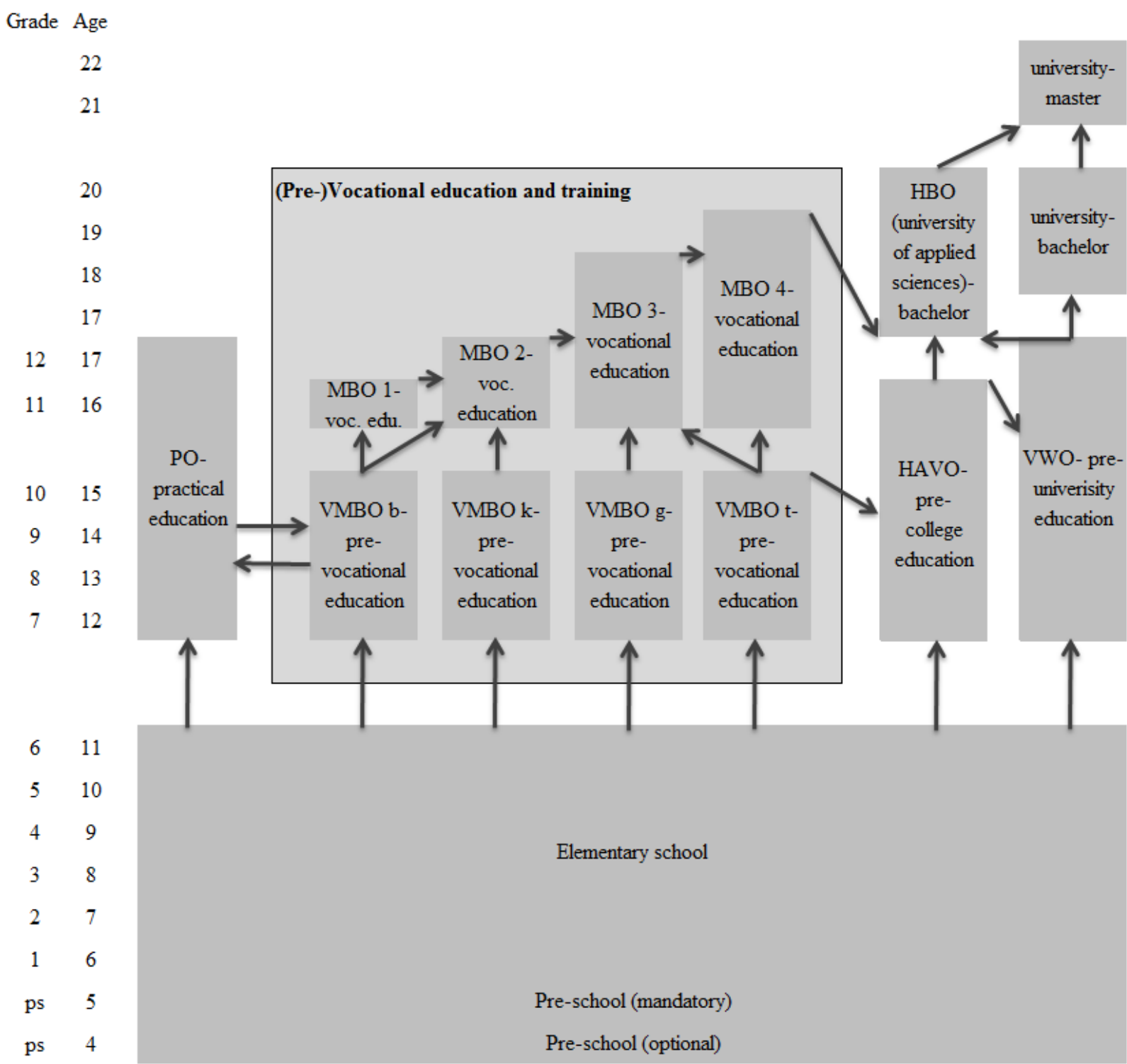

Notes. Compulsory education is till the age of 16 if a start qualification is obtained. A start qualification is a degree in VWO, HAVO, or MBO level 2 and up. If no start qualification is obtained, education is compulsory till the age of 18 . Figure created by the author.

Table 1. Student distribution across tracks in grade 7-9 (average from 2003-2010)

\begin{tabular}{|l|ccc|}
\hline Track & Grade 7 & Grade 8 & Grade 9 \\
\hline po & 0.27 & 0.68 & 0.87 \\
VMBO b & 5.69 & 6.58 & 19.06 \\
VMBO k & 3.15 & 4.44 & 19.81 \\
VMBO g & 0.40 & 0.58 & 9.61 \\
\hline
\end{tabular}




\begin{tabular}{|l|ccc|}
\hline VMBO t & 3.65 & 10.01 & 22.45 \\
Bridge class & 80.38 & 60.24 & 2.20 \\
HAVO & 1.29 & 7.84 & 13.52 \\
VWO & 5.16 & 9.64 & 12.48 \\
Total & 100.00 & 100.00 & 100.00 \\
\hline \multicolumn{2}{|l|}{ Source: Own calculations using DUO data. } \\
\hline
\end{tabular}

As explained in the introduction, the decision on which tracks student go to is solely made by the secondary schools. Secondary schools receive two signals on which they base their track placement decisions: an elementary school exit test score and a track recommendation of the elementary school teacher of the students. Parents can (try to) influence the track decision, but do not have direct influence on the track choice for their children.

\section{Data and methodology}

To look at the effect of PB that takes place before tracking, I make use of a longitudinal data set representative for the Netherlands called COOL ${ }^{5-18}$. COOL $^{5-18}$ started in the academic year 2007-2008 and every three years it collects administrative data from a representative sample of schools, including test scores from centralized tests in each grade, and survey data from the corresponding students, their parents and the schools. My analyses focus primarily on grade 6 and look at the additional effect of PB on the two performance signals secondary school use to decide on track placement, over and above the effect of PB on ability in general. To precisely isolate the additional effect of PB, the general PB effect must be completely controlled for. In the analyses this is done by including previous test scores which are assumed to capture the child's ability, coming both from nature and nurture of parents. Since tests measure ability with error and thus will also control for the effect of PB with error, a second test score is necessary to be able to use one test score as an instrument for the other. Therefore in this paper I use two waves of the data: Students are in grade 3 in 20072008 and in grade 6 in 2010-2011. I then use the grade 3 test score as an instrument for the grade 6 test score.

The data consists of 649 schools in 2007-2008 with a total of 15,473 students in grade 3 and 552 schools participated in 2010-2011 with 12,538 students in grade 6. Unfortunately in total only 62 percent of schools from the first wave participated in the second wave (Driessen $e t$ $a l ., 2012$ ) which leads to a much smaller sample for the longitudinal data set. I exclude 26 students for whom the answers in 2007-2008 do not seem to match with the answers in 20102011 on gender or birth year. Furthermore for my analyses it is necessary to have enough test 
score data and to know parental education. Therefore I exclude another 3,811 students for whom I miss these vital data. My final sample consists of 2,621 students in 156 schools. The attrition and sample selection caused the final sample to deviate to some extent from the representative sample: for instance, parents are lower educated, more immigrants are included and the school size is smaller (see Appendix A). When weights constructed to ensure representativeness for this smaller sample are used, the difference in descriptive statistics on observable characteristics between the representative sample and the weighted sample used in this paper are minimal, as can be seen in Appendix A, which renders confidence in the representativeness of the results. I estimate all the models using weights. However, no large qualitative differences arise when not using the weights, which can be seen in Appendix B.

As a measure of PB of the children the highest obtained educational degree of both the parents is used. The highest obtained educational degree used in this paper is provided by the school and is most often taken from the school administration (Driessen et al., 2012). The reason a school reported measure is used, instead of a parents reported measure, is that the number of missing observations on the school reported data is much smaller. The two measures have a correlation of 0.69 . For those children for whom parental education was not available in grade 6 , grade 3 data was used. Table 2 shows the descriptive statistics. There are four options in parental education: 8.0 percent of parents have at most a primary education degree, 20.0 percent at most a lower vocational education degree (similar to VMBO, prevocational education), 41.2 percent have at most a vocational education degree (MBO), and 30.9 percent of parents have a tertiary education degree (a degree from a university or a university of applied sciences).

In this paper the aim is to study whether there is an additional PB effect (i.e. the secondary PB effect) on the two track decision signals, over and above the general PB effect on ability (i.e. the primary PB effect). To be able to do this I control for this general PB effect since otherwise the PB variable will capture the full PB effect. The PB effect on ability, which has arisen during childhood, is a common occurrence in all children around the world. Since ability itself is not observed, I will use a test score to approximate it. During the school year the students take multiple tests to allow their teachers to follow their progress, also in relation to children at other schools. All schools therefore have the same set of tests available to them provided by a test company in the Netherlands (CITO). Although schools have access to the 
same set of tests, they have discretion in the timing of testing and they grade the tests themselves. However, not all schools take the same set of tests from the available tests. To avoid too many missing observations on the test variables, I combine two tests on reading and two on mathematics. ${ }^{8}$ For both subjects, the two tests are comparable in content, but the score grading distribution is not the same (Driessen et al., 2012). However, the distributions of the different tests approach a normal distribution (not shown). Therefore I standardize both tests and use either one of the tests. I do this for both reading and mathematics.

Table 2. Descriptive statistics

\begin{tabular}{|c|c|c|c|c|c|c|}
\hline Variable & $\begin{array}{c}\text { \# of } \\
\text { students }\end{array}$ & $\begin{array}{c}\text { \# of } \\
\text { schools }\end{array}$ & Mean & Std. Dev. & Min & $\operatorname{Max}$ \\
\hline Math exit test score & 2,621 & 156 & 43.27 & 10.54 & 8.00 & 60.00 \\
\hline Reading exit test score & 2,621 & 156 & 75.64 & 11.50 & 6.00 & 100.00 \\
\hline Math score grade $3(\mathrm{Z})$ & 2,621 & 156 & 0.10 & 0.95 & -4.19 & 3.67 \\
\hline Math score grade 6 & 2,621 & 156 & 0.10 & 0.96 & -4.23 & 3.58 \\
\hline Reading score grade $3(\mathrm{Z})$ & 2,466 & 153 & 0.11 & 1.01 & -1.93 & 5.18 \\
\hline Reading score grade 6 & 2,551 & 152 & 0.13 & 0.99 & -3.82 & 5.04 \\
\hline Recommendation & 2,520 & 156 & 4.87 & 2.21 & 1.00 & 8.00 \\
\hline Parental education & 2,621 & 156 & 3.20 & 0.79 & 1.00 & 4.00 \\
\hline Gender & 2,606 & 156 & 1.51 & 0.50 & 1.00 & 2.00 \\
\hline \# of students in grade 6 & 2,621 & 156 & 15.20 & 12.18 & 1.00 & 67.00 \\
\hline
\end{tabular}

The two outcome variables, the elementary school exit test score and the elementary school teacher recommendation, are as follows: In February of each year (most) students in grade 6 take an elementary school exit test. The test consists of a part on mathematics, reading and world views. The scores on the test range from 500 to 550, while the sub section on math ranges from 0 to 60 and reading from 0 to $100 .^{9}$ The elementary school exit test and the test in grade 6 are taken at approximately the same time with only two months difference. ${ }^{10}$ The elementary school teacher track recommendation is a measure with 15 recommendation options that teachers used. There are so many recommendation options since all forms of bridge classes are possible. For the sake of simplicity I collapsed this set of recommendation to eight: PO \& VMBO b, VMBO k, VMBO g, VMBO t, VMBO t \& HAVO, HAVO, HAVO \& VWO and VWO. These eight groups are of fairly equal size: 12.7 percent of students received a PO \& VMBO b recommendation, 12.8 percent a VMBO k recommendation, 7.5

\footnotetext{
${ }^{8}$ Including a dummy for which test was used does not change the results.

${ }^{9}$ The distribution of the elementary school exit test scores for both reading and mathematics are slightly skewed to the right. However, the reading exit test score is truncated for only 1 student and the math elementary exit test for 16 students. This level of truncation does therefore not necessitate a tobit analysis and thus OLS is used.

${ }^{10}$ All tests were taken between January and March. The CITO test is in February.
} 
percent a VMBO g recommendation, 18.1 percent a VMBO t recommendation, 8.8 percent a VMBO t \& HAVO recommendation, 17.8 percent a HAVO recommendation, 9.0 percent a HAVO \& VWO recommendation and 13.3 percent a VWO recommendation. The elementary school teacher recommendation is given during the spring of grade 6 and theoretically contains all the information on the child's ability level and progress until that point.

Two potential confounding factors play a role. First, since the grade 6 test and the elementary school exit test are both taken within a short period of time, part of the additional PB effect could run through the grade 6 test score. This means that in the analyses of this paper only the additional PB effect of the last two months is analyzed. This can be seen as a lower bound of the additional PB effect. Second, an ability measure in the form of a prior test score will only capture the PB effect adequately if the test score measures ability without error. Since this is unlikely to be the case, I employ an instrumental variable technique to alleviate the measurement error in the grade 6 test score. The instrument I use for this is a test score obtained in grade 3. To look at the effect of PB I will estimate the following model:

$$
\begin{gathered}
\text { TestGrade6 }=\varphi_{0}+\varphi_{1} * \text { TestGrade } 3+\varphi_{3} * P B+u \\
\text { ExitTest }=\beta_{0}+\beta_{1} * \text { Test } \widehat{t G r a} d e 6+\beta_{2} * P B+\varepsilon
\end{gathered}
$$

Model (1-I) depicts the first stage in which measurement error is removed from the test score in grade 6, while models (1-II) depict the second stage for the elementary exit test. Both models are analyzed for the reading and mathematics elementary exit test. Since the test score in grade 3 is used to alleviate the measurement error, $\beta_{1}$ will be an unbiased estimate of the effect of ability on the elementary exit test. $\beta_{2}$ provides a lower bound for the additional PB effect when the parents who help their child study for the elementary exit test in doing so also help the child perform on the grade 6 test. It only provides a lower bound since both the instrument and the instrumented variable are most likely a function of PB.

Equation (2) looks at the additional PB effect on the elementary school teacher recommendation and the main coefficient of interest is $\gamma_{3}$. Due to the discrete and ordinal nature of the elementary school teacher track recommendation, for the models with this as outcome I use an ordered logit.

$$
\text { Recommendation }=\gamma_{0}+\gamma_{1} * \text { TestGrade } 6+\gamma_{2} * \text { ExitTest }+\gamma_{3} * P B+\epsilon
$$


An underlying assumption of ordered logit is that the slope coefficients are the same across categories of the dependent variable, i.e. that the effects of the independent variables are the same across the different steps in the dependent variable. To test whether this is the case in the models estimated here, I first estimated generalized ordered logit models which relax the parallel lines assumption. ${ }^{11}$ However, the parallel line assumption of the ordered logit is only violated for the elementary school exit test scores and since this is not the variable of interest ordered logit is used. To also control for measurement error in this model, the analyses are also done using IV. Since IV requires a continuous dependent variable, I use the 15 options categorical track recommendation variable, rescale it using the ordered logit cut off points and use this variable for the IV.

\section{Results for the elementary school exit test score}

The question asked in this paper is whether there exists an additional PB effect on the track determinants (the elementary school exit test score and the elementary school teacher recommendation) over and above the general $\mathrm{PB}$ effect found on ability. The results for the PB effects on the elementary school exit test score for mathematics and reading are shown in Table 3. The first and fourth column of each panel shows the full PB effect on the math and reading elementary exit test scores. These coefficients contain both the expected PB effect on ability and the additional PB effect on the track determinants. Both in reading and in mathematics parents have a large influence on the test score, with students whose parents have a tertiary education degree scoring one standard deviation higher than students whose parents only have a primary education degree. In columns (2) and (5) the test score in grade 6 is included as a control. Any PB effect that has helped the child over the years to perform better in the test subjects should be included in this test score. As a consequence it can be seen that the effect of PB is lower in columns (2) and (5) than in columns (1) and (4). For mathematics the PB effect in column (2) is even insignificant, except for the highest PB category. However, any remaining PB effect in mathematics and also in reading could be due to measurement error in the test score of grade 6 . If this score is measured with error, it is possible that some remaining general PB effect will be captured by the PB dummies instead of by the grade 6 test score. To remove this measurement error, both columns (3) and (6) present results for models in which the grade 6 test score is instrumented by the test score in grade 3. The content of both tests is comparable and the F statistic (525.9 for mathematics

\footnotetext{
${ }^{11}$ The command gologit2 in Stata, with the autofit option, will only relax the parallel lines constraint for those variables where it is violated
} 
and 382.0 for reading) also shows that the grade 3 is a strong instrument for the grade 6 test. $^{12}$ Looking at the IV estimates, it can first be seen that an additional PB effect on the elementary exit test score exists for reading. The effect of PB is lower when an instrument is used but for reading still a significant effect of PB remains, with students whose parents have a tertiary degree score one sixth of a standard deviation higher than students whose parents have only a primary education degree. The results show that parents have an influence on the reading section of the elementary exit test, but not on the mathematics section. This result could possibly be due to the fact that it is easier for parents to help their child with reading than with math since reading practice in the home is easily available, for instance by reading the newspaper together. ${ }^{13}$ However, since the results are most likely an underestimation, an additional PB effect for math could still exit although less prominent. Second, measurement error does seem to play a large role in columns (2) and (5) since the IV estimates of the effect of the grade 6 test score on the elementary exit test score are higher when the instrument is used. Interestingly, the additional effect of PB decreases much more for those students with a higher PB than for those with a lower PB. The naïve estimates using ordinary least squares seem to indicate a much more favorable position for high FB students compared to lower PB students than they in reality have.

Table 3. Parental background effects on the elementary school exit test score

\begin{tabular}{|l|ccc|ccc|}
\hline & \multicolumn{3}{|c|}{ Math exit test score } & \multicolumn{3}{c|}{ Reading exit test score } \\
& $(1)$ & $(2)$ & $(3)$ & $(4)$ & $(5)$ & $(6)$ \\
& OLS & OLS & IV & OLS & OLS & IV \\
\hline Parent: at most lower vocational & & & & & & \\
education & $3.12^{* *}$ & 0.91 & 0.44 & $3.53 * * *$ & $2.09 * * *$ & $1.43^{*}$ \\
& $(1.53)$ & $(0.80)$ & $(0.76)$ & $(1.12)$ & $(0.75)$ & $(0.74)$ \\
Parent: at most vocational education & $5.18 * * *$ & 0.46 & -0.53 & $7.55^{* * *}$ & $3.48^{* * *}$ & $1.63^{*}$ \\
& $(1.40)$ & $(0.75)$ & $(0.77)$ & $(1.14)$ & $(0.92)$ & $(0.99)$ \\
Parent: at most tertiary education & $10.42^{* * *}$ & $1.84 * *$ & 0.04 & $12.55^{* * *}$ & $5.32^{* * *}$ & $2.05^{* *}$ \\
& $(1.47)$ & $(0.86)$ & $(0.91)$ & $(1.21)$ & $(0.94)$ & $(1.00)$ \\
Grade 6 test score & & $8.89 * * *$ & $10.76^{* * *}$ & & $7.63^{* * *}$ & $11.09 * * *$ \\
& & $(0.22)$ & $(0.35)$ & & $(0.35)$ & $(0.51)$ \\
Constant & & & & & \\
& $36.45^{* * *}$ & $41.29 * * *$ & $42.31 * * *$ & $67.13 * * *$ & $70.88^{* * *}$ & $72.58^{* * *}$ \\
& $(1.37)$ & $(0.75)$ & $(0.79)$ & $(1.09)$ & $(0.80)$ & $(0.82)$ \\
\# of students & & & & & & \\
\# of schools & 2,621 & 2,621 & 2,621 & 2,398 & 2,398 & 2,398 \\
R-squared & 156 & 156 & 156 & 149 & 149 & 149 \\
F excluded Z & 0.09 & 0.68 & 0.66 & 0.10 & 0.51 & 0.43 \\
\hline
\end{tabular}

\footnotetext{
${ }^{12}$ The first stages are not shown, but the results are available from the author upon request.

${ }^{13}$ Controlling for the spoken language at home does not affect the results.
} 
Notes. $* * * \mathrm{p}<0.01, * * \mathrm{p}<0.05, * \mathrm{p}<0.1$. Robust standard errors in parentheses. Cluster on grade 6 schools, weighted models. Estimates in columns (3) and (6) are from a two stage least square model with as excluded instrument for the test score in grade 6 the test score in grade 3.

That the additional PB effect in columns (3) and (6) is lower than in column (1) and (4) does not mean there is no or less of a PB effect. Due to the inclusion of the grade 6 test score, all direct PB effects are captured in this variable. PB therefore most surely has an effect on the elementary exit test. What columns (3) and (6) show is that for mathematics there seems to be no additional PB effect on the elementary school exit test, while there is an additional effect on the reading exit test.

There are three potential issues that could undermine the results on the reading test score. First, using school fixed effects leads to less robust results for reading. School fixed effects could be important to check whether school specific factors matter for the additional PB effect. One example of a confounding school factor could be specific grading practices since the grading of the tests, except for the exit test, are done by the teachers themselves. However, by including school fixed effects, part of the effect of PB is removed since the parents choose the elementary school for their child. Including school fixed effects might therefore lead to a further underestimation of the effect of PB on the elementary exit test score. When the models of columns (1), (2), (4) and (5) of Table 3 are estimated with school fixed effects the results are robust, although smaller in size. But when instrumental variables are used, similar to columns (3) and (6)), there is no longer an additional PB effect on reading. This indicates that it might be school differences which drive the PB effects. Both coefficients drop and the standard errors increase, the last being an indication that the fixed effects models are very demanding on the data. Two reasons why these fixed effects models might show an underestimation are, first, that the amount of variation in parental education is lower within schools than across schools and, second, parents choose the elementary school for their children which means that including school fixed effects lowers the effect of PB. On the other hand, if the school fixed effects lower the additional PB effect it could also mean that the grade 6 test score does not fully capture the general PB effect, which is then picked up by the PB dummies in Table 3, but no longer when school fixed effects are included. This suggests that the aim of this paper, to disentangle the general from the additional PB effect, is hard to accomplish. All in all, the school fixed effect models render less confidence in the results on the reading test scores. 
The second potential issue for the results on the reading test scores could be the sample selection procedure. To see whether the sample selection procedure influenced the results, I also use the full sample (5,643 observations for reading and 5,858 for math) and impute the grade 3 test scores using mean imputation of the lowest stratum. The reading PB effects are still there in the OLS models, but disappear when using IV. There is now also a negative PB effect for the $2^{\text {nd }}$ and $3^{\text {rd }} \mathrm{PB}$ group on math. The negative math results can be explained by divergent schools which were added to the sample in the second wave, for the reading results this does not seem to be the case. ${ }^{14}$ Similarly to the school fixed effect models, these robustness checks reduce the confidence in the positive PB effects on the reading test score, allowing for the alternative conclusion that there is no additional PB effect on the elementary school exit test.

Third, the content of the reading test in grade 6 is different from the content in the elementary school exit test. A large portion of the test coincides, but the exit test contains spelling and grammar while test grade 6 does not. This leaves room for an alternative conclusion that the remaining PB effect I find on the reading elementary school exit test score is due to a general PB effect on the spelling and grammar ability of students.

\section{Results for the track recommendation}

Table 4 shows the results looking at the additional PB effect on the elementary school teacher track recommendation. Also here column (1) gives the estimates of the full PB effect, displayed in odds ratios. The elementary school teacher recommendation is a categorical variable with eight options: PO \& VMBO b, VMBO k, VMBO g, VMBO t, VMBO t \& HAVO, HAVO, HAVO \& VWO and VWO. The estimates in column (1) of Table 4 state that for students whose parents have a tertiary education degree the odds of having the highest track recommendation as compared to the other recommendations are almost 13.5 times greater than for students whose parents only have a primary education degree. This large PB effect can also be seen in the blue solid lines of Figure 2, which shows the predicted probabilities to obtain the eight track recommendations given PB. Students with parents with at most a primary education degree have a predicted probability of 30 percent of obtaining the lowest track recommendation, while students with the highest PB have only have a predicted probability of around three percent. In column (2) of Table 4 also the grade 6 test

\footnotetext{
${ }^{14}$ This statement is based on the significance of imputation dummies and imputation dummy and imputed variable interactions.
} 
scores are included to separate the general PB effect from the additional PB effect, and column (3) also includes the elementary school exit test scores on math and reading. Column (3) shows that for the second highest and highest PB group there remains an additional PB effect on the elementary school teacher recommendation after inclusion of test scores. Figure 2 also shows this decline in influence of PB separately for each track recommendations. ${ }^{15}$ The red dashed lines in Figure 2 shows that the predicted probabilities of obtaining one of the eight track recommendation when controlled for ability still differs across PB groups. The slope of the red dashed line is less steep than the blue solid line, except for the highest prevocational track (fourth lowest) and the lower general track (third highest). The two higher PB groups are less likely to receive a recommendation for the lower tracks and more likely to receive a recommendation for the higher tracks as compared to the other groups. Another way to interpret these results is by looking at how much tertiary educated parents are able to bridge the gap between the lowest and the highest track, which is given in the last row of Table 4. In the model with no controls they are able to bridge 56 percent of the distance between the lowest and the highest track, while in column (3) they able to bridge 13 percent of the distance. When the extended sample is used (5,401 observations) a PB effect exists for the second lowest and the highest PB category. ${ }^{16}$

Table 4. Parental background effects on the elementary school teacher recommendation

\begin{tabular}{|l|cccc|}
\hline & $(1)$ & $(2)$ & $(3)$ & $(4)$ \\
& o. logit & o. logit & o. logit & IV \\
\hline Parent: at most lower vocational & & & & \\
education & $2.05^{* * *}$ & 1.54 & 1.28 & 1.13 \\
& $(0.47)$ & $(0.42)$ & $(0.37)$ & $(0.14)$ \\
Parent: at most vocational education & $4.28^{* * *}$ & $2.30^{* * *}$ & $1.93^{* *}$ & $1.38^{* *}$ \\
& $(0.89)$ & $(0.65)$ & $(0.57)$ & $(0.16)$ \\
Parent: at most tertiary education & $13.49^{* * *}$ & $5.16^{* * *}$ & $3.65^{* * *}$ & $1.62^{* * *}$ \\
& $(3.34)$ & $(1.65)$ & $(1.20)$ & $(0.24)$ \\
Math test score grade 6 & & $5.44 * * *$ & $2.65^{* * *}$ & 1.01 \\
& & $(0.67)$ & $(0.43)$ & $(0.01)$ \\
\hline
\end{tabular}

\footnotetext{
${ }^{15}$ The line indicating the model controlling for ability is almost always below the line where ability is not controlled for, illustrating the fact that including ability measures lowers the effect of parental background. For the VMBO-t, VMBO-t \& HAVO and HAVO track recommendation, this is however not the case. Karlson, Holm and Breen (2012) show that when estimating same-sample nested logit models, it is not possible to compare the coefficients of the different models since the variance of the underlying latent (and thus estimated) variable differs between different models. To correct the estimates for this, the KHB method essentially uses the variance of the underlying variable as estimated in the largest model to estimate the coefficients for the lower level nested models resulting in larger effects of the coefficients of interest in the smaller model. This correction therefore increases the PB effect in the smaller models and makes the decrease due to the inclusion of the grade 6 and the elementary exit test scores even larger. However, the additional PB effect in the largest model still remains which is the reason the corrections were not applied to Table 4 or in Figure 2.

${ }^{16}$ This also hold if the grade 6 test scores are not included, or when the overall elementary exit test score (i.e. not the reading and math parts separately) is included.
} 


\begin{tabular}{|c|c|c|c|c|}
\hline Reading test score grade 6 & & $\begin{array}{c}4.45^{* * * *} \\
(0.40)\end{array}$ & $\begin{array}{c}2.22 * * * \\
(0.25)\end{array}$ & $\begin{array}{c}1.02 * * * \\
(0.01)\end{array}$ \\
\hline Elementary exit test score: math & & & $\begin{array}{c}1.09 * * * \\
(0.01)\end{array}$ & $\begin{array}{c}2.01 * * * \\
(0.41)\end{array}$ \\
\hline Elementary exit test score: reading & & & $\begin{array}{c}1.14 * * * \\
(0.01)\end{array}$ & $\begin{array}{c}2.44 * * * \\
(0.37)\end{array}$ \\
\hline \# of students & 2,452 & 2,452 & 2,452 & 2,307 \\
\hline \# of schools & 152 & 152 & 152 & 149 \\
\hline (Pseudo) R-squared & 0.04 & 0.30 & 0.38 & 0.69 \\
\hline Parent: $\mathrm{HBO} / \mathrm{WO} /($ cut 7 - cut 1$)$ & 0.56 & 0.20 & 0.13 & - \\
\hline F statistic math test grade 6 & - & - & - & 50.66 \\
\hline F statistic reading test grade 6 & - & - & - & 24.24 \\
\hline \multicolumn{5}{|c|}{$\begin{array}{l}\text { Notes. Robust standard errors in parentheses. } * * * \mathrm{p}<0.01, * * \mathrm{p}<0.05, * \mathrm{p}<0.1 \text {. Ordered logit with weights, constants } \\
\text { omitted from table. Odds ratios for the first three columns (eform). Third row from the bottom states: Being from } \\
\text { the highest PB group bridges } 13 \text { percent (column } 3 \text { ) of the distance between the highest and the lowest track. } \\
\text { Calculated using ordered logit coefficients. Pseudo R-squared for the logit models. IV using a continuous version of } \\
\text { the teacher recommendation based upon the ordered logit cut points. To facilitate comparison between the columns } \\
\text { the IV coefficients are displayed as exp(b), similar to the ordered logit odds ratios. }\end{array}$} \\
\hline
\end{tabular}

The measurement error in the grade 6 test scores cannot be removed by an IV model using the current variables, since the elementary school teacher recommendation is a categorical variable. An instrumental variable method cannot be performed using a categorical dependent variable due to its non-linearity. For illustration purposes, Column 4 of Table 4 still presents results from an IV estimation using the full categorical dependent variables with all 15 options. Since the steps in the categorical variable might not be equal for each discrete jump in the categorical variable I rescale the primary school teacher recommendation using the cut points from an ordered logit model looking at the relation between the elementary teacher recommendation and parental education. The cut points are used to transform the track recommendation in the following way: The value for each recommendation option is the average of the two consecutive cut points. The value for the lowest recommendation option is the second lowest value minus the difference between the first and second cut point, while the value for the highest cut point is the second highest recommendation plus the difference between the penultimate and the last cut point. Column 4 of Table 4 presents the estimates for this model. To facilitate the comparison between the different columns, the exponent of the estimates of the IV model is presented. What can be seen is that, similar to the models on the elementary school exit test score, the estimates on PB are lower in the IV model. However, both for the highest and the second highest PB category a significant positive effect of PB exists. As said before, these results are only for illustrative purposes since IV requires a continuous dependent variable. 
Figure 2: Predicted probabilities on the elementary school teacher recommendation per parental background at averages
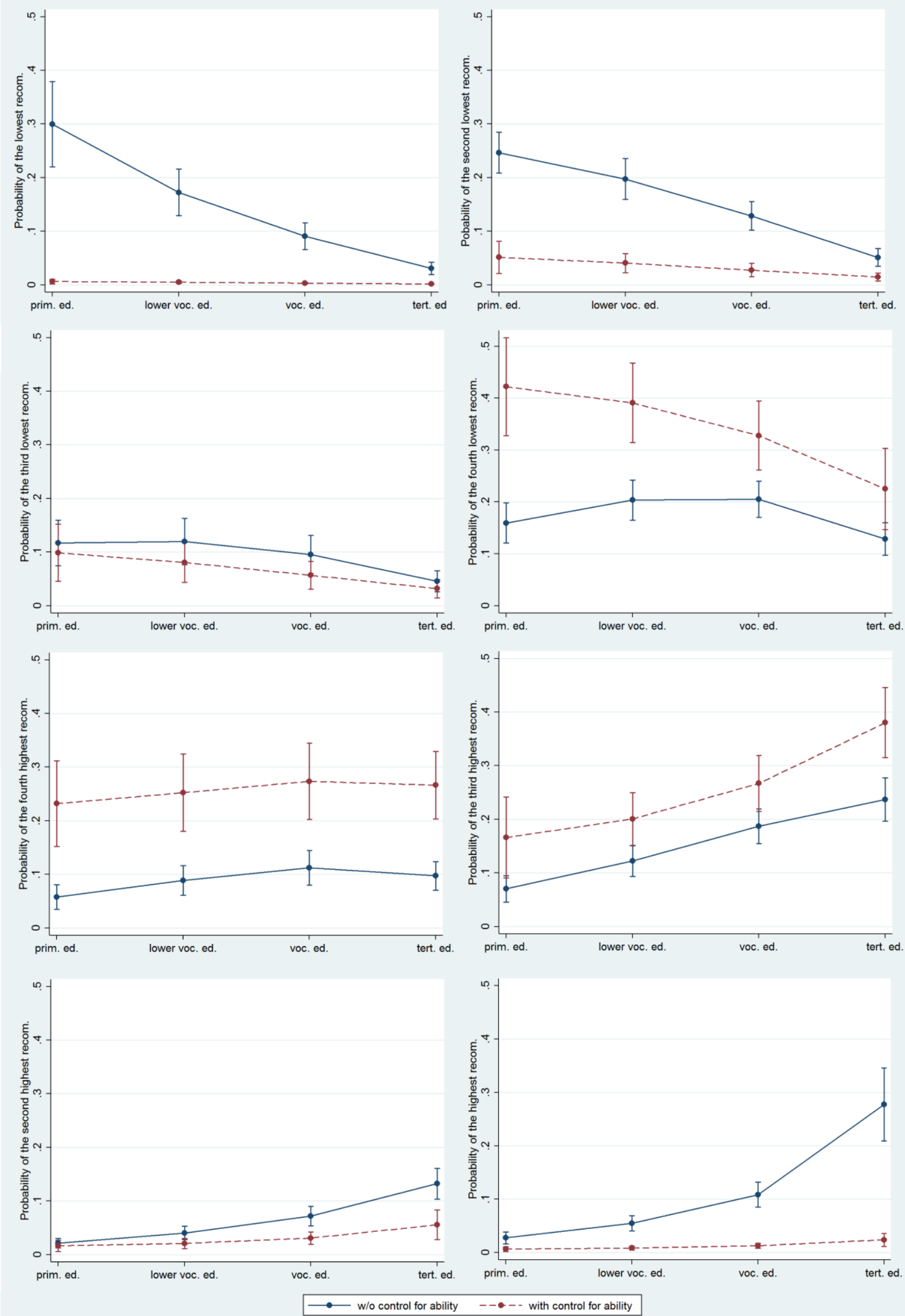


\section{Conclusion}

In this paper I look at whether there exists a parental background (PB) effect on the two track determinants in the Netherlands over and above a PB effect on ability. In the tracked education system of the Netherlands, secondary schools made the track placement decision based on two performance signals: an elementary school exit test score and an elementary school teacher recommendation. Parents have no formal route to exert influence on the track decision. Naturally there always is a general PB effect on performance since parents directly influence the ability of their children.

To investigate whether there is a PB effect on the two track determinants over and above a PB effect on ability, I control for observed ability in the form of a test score in grade 6 . Since this test score measures ability with error, I instrument this with an earlier test score. I find that parents are able to increase their child's reading elementary school exit test score and the higher educated parents are, the more effect they have. I find no such effect on the math exit test score. The existence of a PB effect on the reading test score and not on the math test score can be explained by the easier transmission of reading skills in daily life than math skills. The results on the elementary exit test are however not fully convincing: the significant effects disappear when I use school fixed effects or an extended sample. On the other hand, the results on the elementary exit test score provide a lower bound for the full additional PB effect due to the quick succession of the grade 6 test and the exit test, which leaves room for a larger effect.

On the elementary school teacher track recommendation I find a robust additional PB effect. The odds of having the highest track recommendation as compared to the other recommendations, for students whose parents have a tertiary education degree are between 1.6 and 3.6 times greater than for students whose parents only have a primary education degree.

Summarizing, parents seem to have an influence on the elementary school exit test score and the teacher track recommendation of their child, over and above a PB effect on the child's ability. Whether this is due to parents purposefully or unconsciously exerting influence or due to teachers providing different recommendations based on PB cannot be said based on these results. 


\section{References}

Ammermueller, A. (2005) Educational Opportunities and the Role of Institutions. ZEW Discussion Paper 05-44

Barg, K. (2013) The Influence of Students' Social Background and Parental Involvement on Teachers' School Track Choices: Reasons and Consequences

Black, S, P. Devereux and K. Salvanes (2005) Why the Apple Doesn't Fall Far: Understanding Intergenerational Transmission of Human Capital. American Economic Review, 95, pp. 437-449.

Boudon, R. (1974). Education, Inequality and Social Opportunity, New York, Wiley

Brunello, G., and D. Checchi (2007). Does School Tracking Affect Equality of Opportunity? New International Evidence. Economic Policy, (October), 781-861.

Dollmann, J. (2011) Verbindliche und Unverbindliche Grundschulempfehlungen und Soziale Ungleichheiten am Ersten Bildungsübergang. Kölner Zeitschrift für Soziologie und Sozialpsychologie, 63(4), pp. 431-457.

Driessen, G., L. Mulder, and J. Roeleveld (2012) Cohortonderzoek COOL5-18. Technisch rapport basisonderwijs, tweede meting 2010/11. Nijmegen: ITS/Amsterdam: Kohnstamm Instituut.

Driessen, G., L. Mulder, G. Ledoux, J. Roeleveld, and I. van der Veen (2009) Cohortonderzoek COOL5-18. Technisch rapport basisonderwijs, eerste meting 2007/08. Nijmegen: ITS / Amsterdam: SCO-Kohnstamm Instituut.

Dustmann, C. (2004) Parental Background, Secondary School Track Choice, and Wages. Oxford Economic Papers, 56, pp. 209-230.

Education Inspectorate (2013) Onderwijsverslag 2012-2013. Inspectie van het onderwijs: Den Haag.

Essser, H. (2014) Educational Systems and Educational Inequality. What is With Ability Tracking? In mineo.

Girard and Bastide (1963) La Stratification Sociale et la Démocratisation de l'Enseignement. In: Population, 18(3), pp. 435-472.

Hanushek, E.H. and L. Woessmann (2006) Does Educational Tracking Affect Performance and Inequality? Difference-in-Difference Evidence Across Countries. Economic Journal, 116, pp. C63-C76.

Horn, D. (2013) Diverging Performances: the Detrimental Effects of Early Educational Selection on Equality of Opportunity in Hungary. Research in Social Stratification and Mobility, 32(June), pp. 25-43.

Ichou, M. and L.-A. Vallet (2011). Do All Roads Lead to Inequality? Trends in French Upper Secondary School Analysed with Four Longitudinal Surveys. Oxford Review of Education, 37, pp. 167-194.

Jackson, M. (2013b). Introduction: How is Inequality of Educational Opportunity Generated? The Case for Primary and Secondary Effects. In: Jackson, M. (Ed.) Determined to Succeed? Performance versus Choice in Educational Attainment, pp.1-33. Stanford: Stanford University Press.

Jussim, L. and K. Harber (2005) Teacher Expectations and Self-Fulfilling Prophecies: Knows and Unknowns, Resolved and Unresolved Controversies. Personality and Social Psychology Review, 9(2), pp. 131-155. 
Karlson, K.B., A. Holm and R. Breen (2012) Comparing Regression Coefficients Between Same-sample Nested Models Using Logit and Probit: a New Method. Sociological Methodology, 42, pp. 286-313.

Kingdom of the Netherlands (1981) Wet op het Primair Onderwijs. Hoofdstuk I.

Basisonderwijs. Artikel 42. Onderwijskundig rapport. Law book. The Netherlands.

Korthals, R. (2012) Selection and Tracking in Secondary Education: a Cross Country Analysis of Student Performance and Educational Opportunities, ROA Research Memorandum no. 2012/14.

Landvoigt, T., G. Muehler, and F. Pfeiffer (2007) Duration and Intensity of Kindergarten Attendance and Secondary School Track Choice, ZEW Discussion Papers nr. 07-051. Lavy, V. and E. Sand (2015) On the Origins of Gender Human Capital Gaps: Short and Long Term Consequences of Teachers' Stereotypical Biases. NBER Working Paper Series no. 20909.

Panichella, N. and M. Triventi (2014), Social Inequalities in the Choice of Secondary School. Long-term Trends During Educational Expansion and Reforms in Italy, European Societies.

Schneider, S. L. and N. Tieben (2011). A Healthy Sorting Machine? Social Inequality in the Transition to Upper Secondary Education in Germany. Oxford Review of Education 37, pp. 139-166.

Schuetz G., H.W. Ursprung, and L. Woessmann (2008) Education Policy and Equality of Opportunity. Kyklos, 61(2), pp. 279-308.

Sullivan, A., A. Heath, and C. Rothon (2011), Equalisation or Inflation? Social Class and Gender Differentials in England and Wales. Oxford Review of Education, 37, pp. 215-40.

Tieben, N., P. M. de Graaf, and N. D. de Graaf (2009). Changing Effects of Family Background on Transitions to Secondary Education in the Netherlands. Consequences of Educational Expansion and Reform. Research in Social Stratification and Mobility, 27, pp. 77-90.

Walldinger, F. (2006) Does Tracking Affect the Importance of Family Background on Students' Test Scores? In mineo. www.cepr.org/meets/wkcn/3/3527/papers/Waldinger.pdf.

Woelfel, O. and G. Heineck (2012) Parental Risk Attitudes and Children's Secondary School Track Choice. Economics of Education Review, 31, pp. 727- 743. 


\section{Appendix A- Representative sample}

The main sample used in this paper is a subsample from a large representative sample from Dutch secondary school students. Since a large number of observations have missing values on crucial variables, the main sample contains only about thirty percent of the original sample. To still ensure representativeness, weights are employed in the analyses in this paper. The weights are constructed using the representative sample and are based upon the education of the parents, gender, and two school composition variables: the school average of parental education and the school immigrant percentage. Table A1 shows some descriptive statistics for the full representative sample, the restricted sample used in this paper and the weighted version of the restricted sample. The last column shows the difference in the mean between the two restricted sample and the full representative sample.

Table A1: Descriptive statistics of the different samples

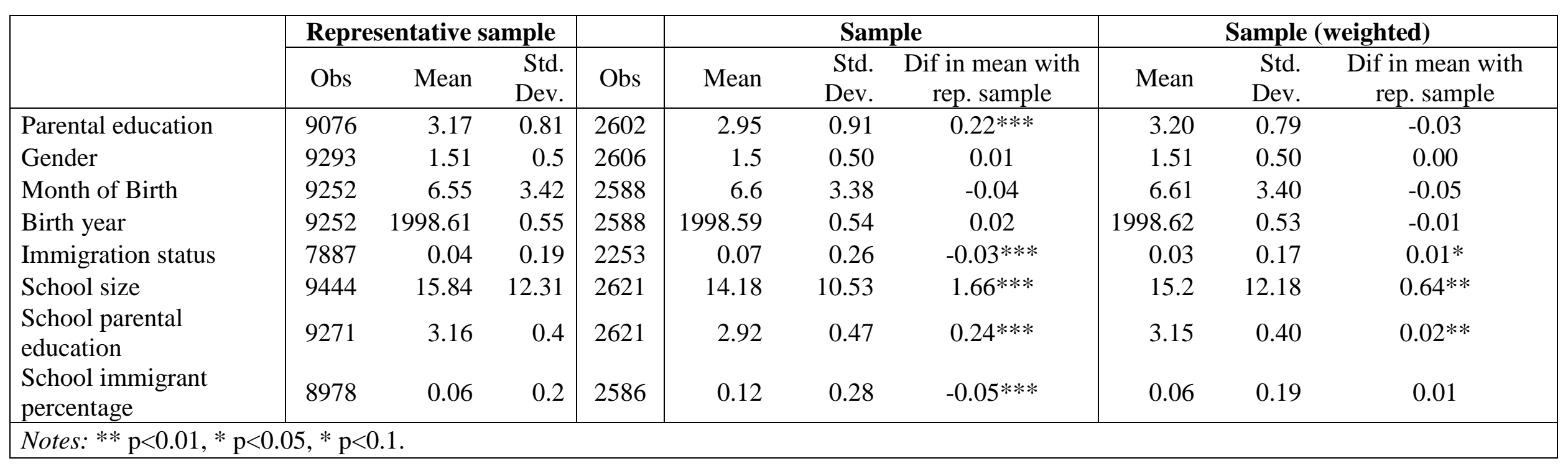




\section{Appendix B- Results without weights}

Table B1 and B2 present the same models as Table 3 and 4 but now not using the weights.

The results are qualitatively the same as described in the main text.

Table B1. Parental background effects on the elementary school exit test (without weights)

\begin{tabular}{|l|c|c|c|c|c|c|}
\hline & \multicolumn{3}{|c|}{ Math exit test score } & \multicolumn{3}{c|}{ Reading exit test score } \\
\hline & $(1)$ & $(2)$ & $(3)$ & $(4)$ & $(5)$ & $(6)$ \\
\hline $\begin{array}{l}\text { Parent: at most lower vocational } \\
\text { education }\end{array}$ & $2.33^{* *}$ & 0.25 & -0.11 & $4.11^{* * *}$ & $2.16^{* * *}$ & $1.41^{* *}$ \\
\hline & $(0.983)$ & $(0.61)$ & $(0.60)$ & $(0.98)$ & $(0.65)$ & $(0.68)$ \\
\hline Parent: at most vocational education & $4.72^{* * *}$ & -0.19 & $-1.03 *$ & $7.87 * * *$ & $3.42^{* * *}$ & $1.70^{* *}$ \\
\hline & $(0.98)$ & $(0.62)$ & $(0.62)$ & $(0.99)$ & $(0.71)$ & $(0.75)$ \\
\hline Parent: at most tertiary education & $10.25^{* * *}$ & $1.19^{*}$ & -0.36 & $13.25^{* * *}$ & $4.75^{* * *}$ & $1.47 * *$ \\
\hline & $(1.02)$ & $(0.67)$ & $(0.69)$ & $(1.08)$ & $(0.73)$ & $(0.74)$ \\
\hline grade 6 test & & $9.13^{* * *}$ & $10.69 * * *$ & & $8.26^{* * *}$ & $11.45^{* * *}$ \\
\hline & & $(0.19)$ & $(0.30)$ & & $(0.31)$ & $(0.43)$ \\
\hline Constant & $36.41^{* * *}$ & $41.64 * * *$ & $42.54 * * *$ & $65.92^{* * *}$ & $70.60^{* * *}$ & $72.41 * * *$ \\
\hline & $(0.97)$ & $(0.61)$ & $(0.63)$ & $(1.00)$ & $(0.64)$ & $(0.66)$ \\
\hline & & & & & & \\
\hline \# of students & 2,621 & 2,621 & 2,621 & 2,398 & 2,398 & 2,398 \\
\hline \# of schools & 156 & 156 & 156 & 149 & 149 & 149 \\
\hline R-squared & 0.10 & 0.70 & 0.68 & 0.12 & 0.54 & 0.47 \\
\hline F excluded Z & & & 559.3 & & & 819.4 \\
\hline
\end{tabular}

Notes. $* * * \mathrm{p}<0.01, * * \mathrm{p}<0.05, * \mathrm{p}<0.1$. Robust standard errors in parentheses. Cluster on grade 6 schools. Estimates in columns (3) and (6) are from a two stage least square model with as excluded instrument for the test score in grade 6 the test score in grade 3 .

Table B2. Parental background effects on the elementary school teacher recommendation (without weights)

\begin{tabular}{|l|c|c|c|c|}
\hline & $(1)$ & $(2)$ & $(3)$ & $(4)$ \\
\hline Parent: at most lower vocational education & o. logit & o. logit & o. logit & IV \\
\hline & $1.93^{* * *}$ & $1.52^{*}$ & 1.29 & 1.19 \\
\hline Parent: at most vocational education & $(0.31)$ & $(0.38)$ & $(0.35)$ & $(0.14)$ \\
\hline & $3.45^{* * *}$ & $1.73^{* *}$ & 1.41 & $1.37 * * *$ \\
\hline Parent: at most tertiary education & $(0.58)$ & $(0.48)$ & $(0.41)$ & $(0.17)$ \\
\hline & $10.87 * *$ & $3.64 * * *$ & $2.57 * * *$ & $1.47 * * *$ \\
\hline Math test grade 6 & $(2.10)$ & $(1.10)$ & $(0.79)$ & $(0.20)$ \\
\hline & & $6.29^{* * *}$ & $3.14 * * *$ & $2.56^{* * *}$ \\
\hline Reading test grade 6 & & $(0.68)$ & $(0.48)$ & $(0.51)$ \\
\hline & & $4.51 * * *$ & $2.30^{* * *}$ & $2.33^{* * *}$ \\
\hline
\end{tabular}




\begin{tabular}{|l|c|c|c|c|}
\hline Elementary exit test: math & & & $1.08^{* * *}$ & 1.00 \\
\hline & & & $(0.01)$ & $(0.01)$ \\
\hline Elementary exit test: reading & & & $1.13^{* * *}$ & $1.02^{* * *}$ \\
\hline & & & $(0.01)$ & $(0.01)$ \\
\hline \# of students & 2,452 & 2,452 & 2,452 & 2,307 \\
\hline \# of schools & 152 & 152 & 152 & 149 \\
\hline (Pseudo) R-squared & 0.06 & 0.41 & 0.49 & 0.70 \\
\hline $\begin{array}{l}\text { Notes. Robust se in parentheses. *** p<0.01, ** p<0.05, * p<0.1. Ordered logit with weights, constants omitted } \\
\text { from table. Odds ratios for the first three columns (eform). Pseudo R-squared for the logit models. IV using a } \\
\text { continuous version of the teacher recommendation based upon the ordered logit cut points. For comparison } \\
\text { reasons are the IV coefficient displayed as exp(b), similar like the ordered logit coefficients. }\end{array}$ \\
\hline
\end{tabular}

